\title{
Comparison of the effects of normal and low blood pressure regulation on the optic nerve sheath diameter in robot assisted laparoscopic radical prostatectomy
}

Received December 15, 2020

Revised February 22, 2021

Accepted February 22, 2021

\section{Corresponding author}

Ji Hee Hong, M.D., Ph.D.

Department of Anesthesiology and

Pain Medicine, Keimyung University

Dongsan Hospital, 1035 Dalgubeol-

daero, Dalseo-gu, Daegu 42601,

Korea

Tel: 82-53-258-7767

Fax: 82-53-258-6288

E-mail: swon13@daum.net

\section{Ji Hoon Park, Ji Hee Hong, Ji Seob Kim, and Hyung Jun Kim}

Department of Anesthesiology and Pain Medicine, Keimyung University Dongsan Hospital, Daegu, Korea

Background: Robot-assisted laparoscopic radical prostatectomy is an advanced and popular surgical technique. However, increased intracranial pressure which is caused by $\mathrm{CO}_{2}$ pneumoperitoneum and Trendelenburg position is the main cerebrovascular effect. Measurement of optic nerve sheath diameter using ocular ultrasound is a noninvasive and reliable method for the assessment of intracranial pressure. The primary endpoint of this study was to identify whether low blood pressure regulation has any benefit in attenuating an increase of optic nerve sheath diameter during robot-assisted laparoscopic radical prostatectomy.

Methods: Optic nerve sheath diameter and cerebral oxygen saturation were measured at baseline (supine position), one and two hours after pneumoperitoneum and Trendelenburg position respectively, and after return to supine position in normal $(n=27)$ and low blood pressure groups $(n=24)$.

Results: Mean optic nerve sheath diameter values measured at one and two hours after pneumoperitoneum and Trendelenburg position were significantly increased compared to the baseline value $(P<0.001$ in normal blood pressure group; $P=0.003$ in low blood pressure group). However, the mean optic nerve sheath diameter and cerebral oxygen saturation measured at any of the time points as well as degrees of change between the two groups did not show any significant changes. The peak values of optic nerve sheath diameter in normal and low blood pressure groups demonstrated $14.9 \%$ and $9.2 \%$ increases, respectively.

Conclusions: Low blood pressure group demonstrated an effect in maintaining an increase of optic nerve sheath diameter less than $10 \%$ during $\mathrm{CO}_{2}$ pneumoperitoneum and Trendelenburg position.

Keywords: Blood pressure; Cerebral oxygen saturation; Optic nerve sheath diameter; Pneumoperitoneum; Trendelenburg position.

This is an Open Access article distributed under the terms of the Creative Commons Attribution Non-Commercial License (http://creativecommons.org/licenses/by-nc/4.0) which permits unrestricted non-commercial use, distribution, and reproduction in any medium, provided the original work is properly cited.

Copyright (C) the Korean Society of Anesthesiologists, 2021 


\section{INTRODUCTION}

Robot-assisted laparoscopic radical prostatectomy (RAL$\mathrm{RP}$ ) is an advanced and popular surgical technique with benefits of reduced intraoperative bleeding, less postoperative pain, good surgical field and shorter hospital stay [1,2]. However, RALRP requires $\mathrm{CO}_{2}$ pneumoperitoneum with steep Trendelenburg position to enhance the clarity of the surgical field, which causes unwanted hemodynamic, respiratory, and cerebrovascular events.

Among such adverse events, increased intracranial pressure (ICP) which is caused by $\mathrm{CO}_{2}$ pneumoperitoneum and Trendelenburg position either independently or in conjunction is the main cerebrovascular effect [1,3-5]. Early diagnosis and proper management of increased ICP play an essential role in preventing further brain damage. In spite of the importance of increased ICP during surgery, it is rarely monitored intraoperatively due to the invasiveness of the ICP measurement. Direct measurement of ICP involves measuring pressure in the ventricle or the brain parenchyma directly [6]. However, such an invasive method makes the popular use of ICP monitoring difficult. An alternative non-invasive method for ICP assessment is using optic nerve sheath diameter (ONSD) measurement by ultrasonography [6-8].

Measurement of ONSD using ocular ultrasound is a noninvasive and reliable method for the assessment of ICP. Numerous studies have proven that ONSD measured by ocular ultrasound correlates well with the degree of ICP changes [9-13]. Also, this measurement technique has shown excellent intra-observer and inter-observer reproducibility (0.25$0.3 \mathrm{~mm})[14,15]$.

Previous study which investigated the elevation of ICP during RALRP suggested that postoperative ONSD changes were significantly associated with regulation of mean arterial pressure (MAP) [2]. According to this study, a $10 \mathrm{mmHg}$ increase in MAP resulted in a $0.023 \mathrm{~mm}$ increase in postoperative ONSD. However, only a small number of participants were studied to identify this correlation between MAP and ONSD. Moreover, this study did not demonstrate any range or degree of MAP regulation during the entire study period [2].

Cerebral circulation can be assessed by measurement of regional cerebral oxygen saturation $\left(\mathrm{rSO}_{2}\right)$ values using near infrared spectroscopy. Previous study which evaluated changes in $\mathrm{rSO}_{2}$ during RALRP demonstrated that changes of $\mathrm{rSO}_{2}$ correlated with MAP and $\mathrm{PaCO}_{2}$ [16].

The purpose of this study was to identify whether low
MAP regulation has any benefit in attenuating an increase in ONSD. The primary endpoint of this study was to compare the differences in ONSD changes during surgery between the normal and hypotensive groups. The secondary endpoint of this study was to compare the changes of ONSD and $\mathrm{rSO}_{2}$ when MAP was tightly regulated between pressure ranges corresponding to normal (95-105 $\mathrm{mmHg}$ ) and low (65-75 mmHg) during RALRP.

\section{MATERIALS AND METHODS}

\section{Subjects}

This prospective and randomized study was approved by the Institutional Review Board (no. 19-07-049) of our institution. Written and verbal information about the potential benefits and risks of the study were provided. All participants provided written informed consent. This study was registered before patient enrollment at clinicalTrials.gov (NCT04339244, Date of registration: 6th-April-2020).

Patients with American Society of Anesthesiologists class I to II who were scheduled for an elective RALRP using the da Vinci ${ }^{\text {Si }}$ robot system (Intuitive Surgical Inc., USA) between April 2020 and September 2020 were included in this study.

Patients with preexisting ophthalmic and cerebrovascular disease or previous history of brain or ophthalmic surgery were excluded. Patients with a previous history of uncontrolled hypertension in spite of using antihypertensive medication were excluded.

\section{Anesthetic management}

The participants arrived in the operating room without premedication. Electrocardiography, pulse oximetry and noninvasive blood pressure monitoring were applied. General anesthesia was induced with propofol $1.5 \mathrm{mg} / \mathrm{kg}$, rocuronium bromide $0.9 \mathrm{mg} / \mathrm{kg}$ and remifentanil $1 \mu \mathrm{g} / \mathrm{kg}$. After successful tracheal intubation, mechanical ventilation of volume control mode was performed with a tidal volume of 8-10 $\mathrm{ml} / \mathrm{kg}$ and an adjusted respiratory rate to maintain an end-tidal $\mathrm{CO}_{2}\left(\mathrm{EtCO}_{2}\right)$ of 30 to $35 \mathrm{mmHg}$ during surgery.

For the purpose of continuous arterial blood pressure monitoring and sampling for arterial blood gas analysis, radial artery cannulation was performed. Continuous cardiac output was measured directly from this arterial line (Flotrac $^{\mathrm{TM}}$, Edward Life Science, USA). Anesthesia was maintained with 1 to 1.5 minimum alveolar concentration of sevo- 
flurane in $60 \%$ oxygen/air and remifentanil 0.05 to $0.3 \mu \mathrm{g} / \mathrm{kg} /$ min. An adequate anesthetic depth was maintained using a SedLine monitor (SedLine ${ }^{\mathrm{TM}}$, Masimo Corp., USA) and a range of 25-50 patient state index was targeted during surgery. An $\mathrm{rSO}_{2}$ was assessed during surgery. Cerebral oximeter sensors were applied $2 \mathrm{~cm}$ above the eyebrow on the left and right sides of the forehead bilaterally before induction of anesthesia. The value of $\mathrm{rSO}_{2}$ was continuously monitored using $\mathrm{O} 3$ regional oximetry ( $\operatorname{Root}^{\circledR}$, Masimo Corp., USA).

$\mathrm{CO}_{2}$ was infused with an intra-abdominal pressure of 15$20 \mathrm{mmHg}$ using the da Vinci ${ }^{\text {Si }}$ robot system while the patient's position was supine. Trendelenburg position was applied to 30-degrees. During the period of $\mathrm{CO}_{2}$ pneumoperitoneum, minute ventilation was regulated to maintain an $\mathrm{EtCO}_{2}$ of 30 to $35 \mathrm{mmHg}$ by adjusting the respiratory rate.

\section{Group allocation}

This study focused on measuring the ONSD using ocular ultrasonography under different MAP regulation. Participants in the normal and low blood pressure groups were randomly assigned to be controlled to either a MAP of 95-105 $\mathrm{mmHg}$ (normal blood pressure group) and 65-75 $\mathrm{mmHg}$ (low blood pressure group) using a computer-generated randomization table. MAP was mainly regulated using the target concentration of remifentanil. In the low blood pressure group, MAP was regulated between 65-75 $\mathrm{mmHg}$ using remifentanil at 0.2 to $0.3 \mu \mathrm{g} / \mathrm{kg} / \mathrm{min}$. In normal blood pressure group, MAP was regulated within 95-105 mmHg using remifentanil 0.05 to $0.2 \mu \mathrm{g} / \mathrm{kg} / \mathrm{min}$. Strict regulation of MAP in normal and low blood pressure groups was targeted. However, transient MAP changes either above or below assigned pressure ranges for less than one minute were allowed without using any blood pressure regulating medications.

\section{Measurement of ONSD}

A single trained investigator with more than 200 scans of ONSD measurement and fully experienced with previous studies $[1,17]$ conducted this ultrasonographic measurement. This investigator was blinded to the group assignment. Transorbital sonography using a hockey stick probe (Logiq S8, GE Healthcare, USA) was performed to measure ONSD. The power output was reduced (mechanical index, 0.2 ; thermal index, 0 ) to minimize the risk of ultrasound -induced eye injury. Participants were asked to close their eyes and a sterile gel was applied on each closed upper eye- lid. The hockey stick probe was placed gently to minimize the exerted pressure on eyeball. The probe was moved using heel-toe method to capture the best axial image of the orbit in the plane of the optic nerve. The depth parameter was controlled within $3.0-4.0 \mathrm{~cm}$. ONSD was measured $3 \mathrm{~mm}$ posterior to the optic nerve head (Fig. 1) $[13,17,18]$. ONSD images were obtained when the postural effects were stabilized with no further external stimuli.

Each ONSD was measured serially in each eye at the following time points: awake state in supine position before anesthesia induction (baseline, T0), one hour after 30-degree Trendelenburg position with $\mathrm{CO}_{2}$ pneumoperitoneum (T1), two hours after 30-degree Trendelenburg position with $\mathrm{CO}_{2}$ pneumoperitoneum (T2), and $10 \mathrm{~min}$ after returning to supine position without $\mathrm{CO}_{2}$ pneumoperitoneum at the end of RALRP (T3).

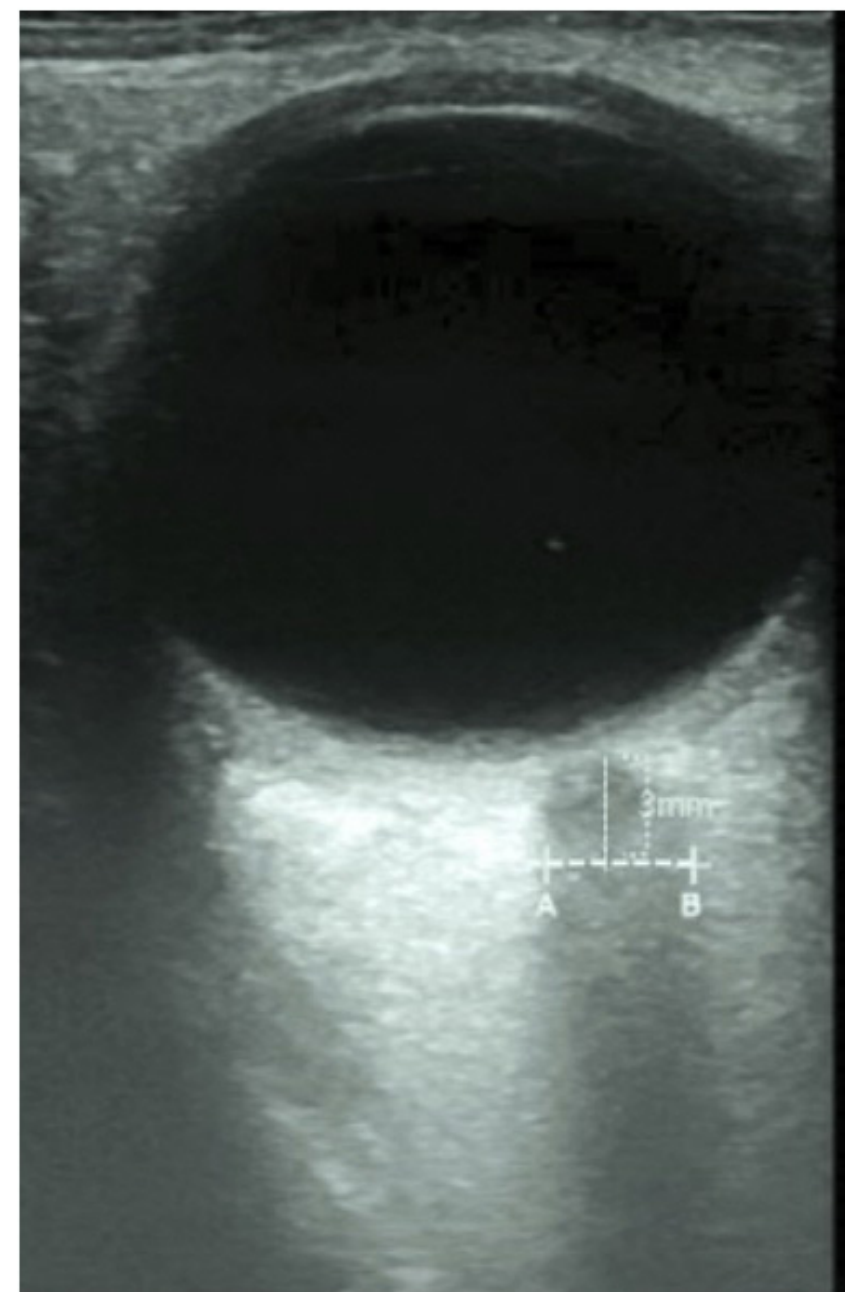

Fig. 1. Measurement of optic nerve sheath diameter by ultrasonography. Axial images of the orbit were acquired in the plane of the optic nerve. Optic nerve sheath diameters were measured 3 $\mathrm{mm}$ posterior to the optic nerve head (A-B). 
At each time point, to obtain more reliable value of ONSD, this measurement was performed twice on the right and twice on the left sides of the optic nerve, respectively. Therefore, the average of the four values was considered to be the final ONSD at each time point. If the measured ONSD was more than $5.5 \mathrm{~mm}$ which was the cut-off point used in a previous study, such patients were considered to have increased ICP [12].

The ONSD, $\mathrm{rSO}_{2}$, heart rate, mean arterial pressure and cardiac output were examined from T0 to T3. The parameters regarding respiratory mechanics and arterial blood gas analysis were examined from $\mathrm{T} 1$ to $\mathrm{T} 3$.

In addition, the Trendelenburg and pneumoperitoneum time, operation and anesthesia time, intraoperative blood loss, and volumes of administered fluid were recorded.

\section{Statistical analysis}

This study was designed to identify whether there would be any differences in ONSD according to MAP regulation. Previous study demonstrated that a difference in ONSD > $0.5 \mathrm{~mm}$ ( $10 \%$ of mean ONSD in asymptomatic normal adults [mean ONSD $4.9 \mathrm{~mm}$ ]) would be clinically relevant [12]. Given a $5 \%$ two-tailed significance level, a power of $80 \%$ and a dropout rate of $15 \%, 24$ patients per group were required to detect a mean difference of $0.5 \mathrm{~mm}$ between ONSD in normal and low blood pressure groups.

All variables were reported as mean \pm SD. Patient characteristics and operative data were compared by unpaired t-test. Except for $\mathrm{ONSD}$ and $\mathrm{rSO}_{2}$, intergroup comparisons for repeated measures, including hemodynamic and respiratory parameters were performed by unpaired t-test with Bonferroni correction. Repeated ONSD and $\mathrm{rSO}_{2}$ measurements were analyzed by linear mixed models for random and fixed effects between the two groups. The Shapiro-Wil- kes test was applied before performing the LMM and the variables were distributed normally.

Intergroup comparison of changes in ONSD over time was performed by group-by-time interaction. All statistical values were two-tailed, and $\mathrm{P}$ values $<0.05$ were considered to be statistically significant. Statistical evaluations were performed using SPSS version 22.0 (IBM Corp., USA).

\section{RESULTS}

Eligibility was assessed in 58 patients and 51 of these patients completed this study without dropout. Two patients refused to participate in this study and five patients were excluded due to a failure of proper MAP regulation to the assigned group. Therefore, final enrolled participants were 51 patients (Fig. 1). Patient characteristics and intraoperative data are described in Table 1.

Mean blood pressure of the low blood pressure group was significantly lower than the normal blood pressure group from T1 to T3 (Table 2, P = 0.001). Respiratory mechanics and arterial blood gas analysis did not show any significant changes between normal and low blood pressure groups (Table 3).

Both normal and low blood pressure groups showed significant increases of ONSD according to time. Mean ONSD values measured at $\mathrm{T} 1$ and $\mathrm{T} 2$ significantly increased compared to the baseline value at T0 (Table $4, \mathrm{P}<0.001$ in normal blood pressure group; $\mathrm{P}=0.003$ in low blood pressure group). However, the mean ONSD values measured at any of the time points and degrees of changes (T1-T0, T2-T0, and T3-T0) between two groups did not show any significant changes. Normal and low blood pressure groups showed peak value of ONSD at T2 and T1, respectively (Table 4, Fig. 2). The peak value of ONSD in normal and low blood pressure groups demonstrated $14.9 \%$ (T2 vs. T0) and 9.2\% (T1 vs. T0)

Table 1. Patient Demographics and Intraoperative Data Assigned to Normal Blood Pressure or Low Blood Pressure Group during Robotassisted Laparoscopic Radical Prostatectomy

\begin{tabular}{lccc}
\hline \multicolumn{1}{c}{ Variable } & Normal blood pressure group $(\mathrm{n}=27)$ & Low blood pressure group $(\mathrm{n}=24)$ & $\mathrm{P}$ value \\
\hline Age $(\mathrm{yr})$ & $68.3 \pm 6.1$ & $68.8 \pm 6.3$ & 0.782 \\
$\mathrm{BMI}\left(\mathrm{kg} / \mathrm{m}^{2}\right)$ & $25.5 \pm 2.7$ & $25.5 \pm 2.6$ & 0.951 \\
Trendelenburg and pneumoperitoneum time $(\mathrm{min})$ & $127.9 \pm 21.7$ & $138.6 \pm 33.4$ & 0.182 \\
Operation time $(\mathrm{min})$ & $167.4 \pm 26.7$ & $174.2 \pm 32.5$ & 0.423 \\
Anesthesia time $(\mathrm{min})$ & $214.8 \pm 28.3$ & $217.9 \pm 37.2$ & 0.741 \\
Intraoperative blood loss $(\mathrm{ml})$ & $244.4 \pm 95.4$ & $237.5 \pm 90.0$ & 0.792 \\
Intraoperative fluid intake $(\mathrm{ml})$ & $1,192.6 \pm 277.2$ & $1,354.2 \pm 321.7$ & 0.063 \\
\hline
\end{tabular}

Values are presented as mean \pm SD. BMI: body mass index. 
Table 2. Hemodynamic Parameters during Robot-assisted Laparoscopic Radical Prostatectomy in Normal Blood Pressure and Low Blood Pressure Groups

\begin{tabular}{lccc}
\hline Hemodynamic parameters & Normal blood pressure group $(\mathrm{n}=27)$ & Low blood pressure group $(\mathrm{n}=24)$ & Adjusted $\mathrm{P}$ value \\
\hline Heart rate (beats/min) & & & \\
T0 & $67.7 \pm 16.6$ & $69.7 \pm 9.8$ & 0.592 \\
T1 & $65.1 \pm 12.5$ & $63.9 \pm 9.8$ & 0.701 \\
T2 & $66.5 \pm 11.2$ & $63.7 \pm 8.7$ & 0.442 \\
T3 & $69.7 \pm 11.7$ & $64.5 \pm 10.0$ & 0.103 \\
Mean arterial pressure (mmHg) & & & 0.974 \\
T0 & $93.6 \pm 9.4$ & $93.3 \pm 9.6$ & 0.001 \\
T1 & $97.5 \pm 5.2$ & $69.0 \pm 8.0$ & 0.001 \\
T2 & $97.0 \pm 8.7$ & $68.5 \pm 9.4$ & 0.001 \\
T3 & $95.1 \pm 4.8$ & $67.6 \pm 8.0$ & \\
Cardiac output (L/min) & & & 0.362 \\
T0 & $5.1 \pm 1.3$ & $4.8 \pm 0.8$ & 0.101 \\
T1 & $4.2 \pm 1.4$ & $3.6 \pm 0.7$ & 0.432 \\
T2 & $4.1 \pm 1.3$ & $3.8 \pm 0.7$ & 0.211 \\
T3 & $5.2 \pm 1.5$ & $4.7 \pm 1.1$ & \\
\hline
\end{tabular}

Values are presented as mean \pm SD. Adjusted $\mathrm{P}$ value indicates the Bonferroni-corrected $\mathrm{P}$ value. T0, supine position before anesthesia induction (baseline); T1, $1 \mathrm{~h}$ after 30-degree Trendelenburg position with $\mathrm{CO}_{2}$ pneumoperitoneum; T2, $2 \mathrm{~h}$ after 30-degree Trendelenburg position with $\mathrm{CO}_{2}$ pneumoperitoneum; T3, 10 min after returning to supine position without $\mathrm{CO}_{2}$ pneumoperitoneum at the end of surgery.

Table 3. Respiratory Mechanics and Arterial Blood Gas Analysis during Robot-assisted Laparoscopic Radical Prostatectomy in Normal Blood Pressure and Low Blood Pressure Groups

\begin{tabular}{|c|c|c|c|}
\hline Respiratory parameters & Normal blood pressure group $(n=27)$ & Low blood pressure group $(n=24)$ & Adjusted $\mathrm{P}$ value \\
\hline \multicolumn{4}{|c|}{ Peak inspiratory pressure $\left(\mathrm{cmH}_{2} \mathrm{O}\right)$} \\
\hline $\mathrm{T} 1$ & $23.3 \pm 4.9$ & $24.1 \pm 3.5$ & 0.512 \\
\hline $\mathrm{T} 2$ & $23.5 \pm 3.8$ & $24.1 \pm 3.8$ & 0.591 \\
\hline T3 & $14.7 \pm 5.0$ & $13.7 \pm 1.9$ & 0.373 \\
\hline \multicolumn{4}{|l|}{ Respiratory rate (beats/min) } \\
\hline $\mathrm{T} 1$ & $13.6 \pm 1.4$ & $13.5 \pm 1.6$ & 0.762 \\
\hline $\mathrm{T} 2$ & $14.6 \pm 1.6$ & $14.1 \pm 2.0$ & 0.261 \\
\hline T3 & $13.8 \pm 1.7$ & $14.1 \pm 2.4$ & 0.602 \\
\hline \multicolumn{4}{|l|}{ End tidal $\mathrm{CO}_{2}(\mathrm{mmHg})$} \\
\hline $\mathrm{T} 1$ & $33.4 \pm 4.1$ & $32.9 \pm 3.4$ & 0.593 \\
\hline $\mathrm{T} 2$ & $34.6 \pm 4.3$ & $33.8 \pm 4.5$ & 0.524 \\
\hline T3 & $36 \pm 4.5$ & $36 \pm 5.8$ & 0.992 \\
\hline \multicolumn{4}{|l|}{ End tidal sevoflurane (\%) } \\
\hline $\mathrm{T} 1$ & $1.8 \pm 0.3$ & $1.9 \pm 0.5$ & 0.991 \\
\hline $\mathrm{T} 2$ & $2.1 \pm 0.5$ & $2.2 \pm 0.2$ & 0.991 \\
\hline T3 & $2.3 \pm 0.2$ & $2.2 \pm 0.2$ & 0.992 \\
\hline \multicolumn{4}{|l|}{$\mathrm{PaCO}_{2}(\mathrm{mmHg})$} \\
\hline $\mathrm{T} 1$ & $41.1 \pm 4.8$ & $41.6 \pm 3.8$ & 0.992 \\
\hline $\mathrm{T} 2$ & $44.6 \pm 4.9$ & $42.9 \pm 5.5$ & 0.561 \\
\hline T3 & $43.2 \pm 4.2$ & $44.8 \pm 8.1$ & 0.361 \\
\hline \multicolumn{4}{|l|}{$\mathrm{PaO}_{2}(\mathrm{mmHg})$} \\
\hline $\mathrm{T} 1$ & $165.0 \pm 22.5$ & $165.6 \pm 18.1$ & 0.991 \\
\hline $\mathrm{T} 2$ & $182.6 \pm 32.1$ & $182.7 \pm 28.5$ & 0.992 \\
\hline T3 & $186.0 \pm 28.5$ & $186.1 \pm 34.1$ & 0.994 \\
\hline
\end{tabular}

Values are presented as mean \pm SD. Adjusted $\mathrm{P}$ value indicates the Bonferroni-corrected $\mathrm{P}$ value. TO, supine position before anesthesia induction (baseline); T1, $1 \mathrm{~h}$ after 30-degree Trendelenburg position with $\mathrm{CO}_{2}$ pneumoperitoneum; T2, $2 \mathrm{~h}$ after 30-degree Trendelenburg position with $\mathrm{CO}_{2}$ pneumoperitoneum; T3, 10 min after returning to supine position without $\mathrm{CO}_{2}$ pneumoperitoneum at the end of surgery. 
increases, respectively. Twenty four patients $(24 / 27,88.8 \%)$ in the normal blood pressure group and 16 patients $(16 / 24$, $66.6 \%$ ) in the low blood pressure group showed a value of ONSD above $5.5 \mathrm{~mm}(\mathrm{P}=0.05$; the cutoff value for prediction of increased ICP) [12], and these patients did not experience a decrease of $\mathrm{rSO}_{2}$ or any neurologic complication.

The mean $\mathrm{rSO}_{2}$ values of the low blood pressure group showed higher values compared to normal blood pressure group from T0 to T3. However, this difference did not show any significant changes (Table 5, Fig. 3). Neurologic complications were not observed in any of the enrolled patients during the postoperative period in both groups.

\section{DISCUSSION}

The effect of $\mathrm{CO}_{2}$ pneumoperitoneum and steep Trendelenburg position during RALRP on ICP warrants a careful consideration. In this study, an increase in ONSD of more

Table 4. Optic Nerve Sheath Diameter during Robot-assisted Laparoscopic Radical Prostatectomy in Normal Blood Pressure and Low Blood Pressure Groups

\begin{tabular}{lccc}
\hline $\begin{array}{c}\text { Optic nerve sheath diameter and } \\
\text { changes in diameter }\end{array}$ & Normal blood pressure group $(\mathrm{n}=27)$ & Low blood pressure group $(\mathrm{n}=24)$ & Adjusted $\mathrm{P}$ value \\
\hline Optic nerve sheath diameter $(\mathrm{mm})$ & & $5.33 \pm 0.46$ \\
T0 & $5.31 \pm 0.48$ & $5.82 \pm 0.5^{\dagger}$ \\
T1 & $6.0 \pm 0.47^{*}$ & $5.77 \pm 0.47^{\dagger}$ \\
T2 & $6.1 \pm 0.59^{\ddagger}$ & $5.71 \pm 0.57$ \\
T3 & $5.87 \pm 0.45$ & & 0.631 \\
Changes in optic nerve sheath diameter & & $0.49 \pm 0.50$ \\
(mm) & $0.69 \pm 0.37$ & $0.44 \pm 0.50$ \\
T1-T0 & $0.79 \pm 0.50$ & $0.38 \pm 0.61$ \\
T2-T0 & $0.56 \pm 0.43$ & 0.772 \\
T3-T0 & & 0.142 \\
\hline
\end{tabular}

Values are presented as mean \pm SD. Adjusted $P$ value indicates the Bonferroni-corrected $P$ value. TO, supine position before anesthesia induction (baseline); T1, $1 \mathrm{~h}$ after 30-degree Trendelenburg position with $\mathrm{CO}_{2}$ pneumoperitoneum; T2, $2 \mathrm{~h}$ after 30-degree Trendelenburg position with $\mathrm{CO}_{2}$ pneumoperitoneum; T3, 10 min after returning to supine position without $\mathrm{CO}_{2}$ pneumoperitoneum at the end of surgery. *T1 vs. TO, $\mathrm{P}<0.001 ;{ }^{\dagger} \mathrm{T} 1$ vs. T0 and T2 vs. T0, $\mathrm{P}=0.003 ;{ }^{\ddagger}$ T2 vs. TO, $\mathrm{P}=0.006$.

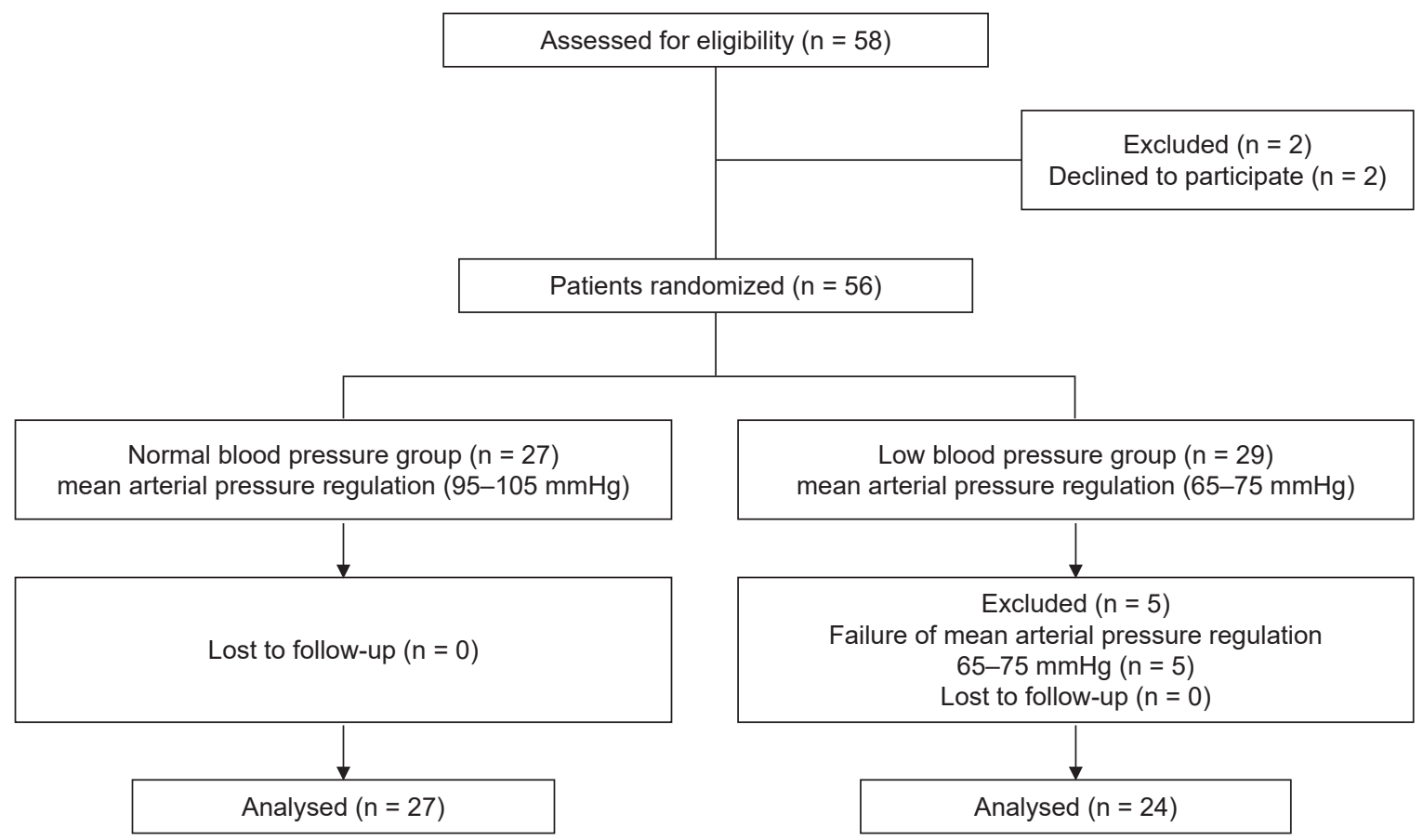

Fig. 2. CONSORT diagram of patient recruitment. CONSORT: consolidated standards of reporting trials. 
than $0.5 \mathrm{~mm}$, which represents a $10.0 \%$ increase compared to supine position without pneumoperitoneum, was considered to be the result of increased intracranial pressure [12]. The results of our study demonstrated that an increase of ONSD of $14.9 \%$ was observed during $\mathrm{CO}_{2}$ pneumoperitoneum and Trendelenburg position in the normal blood pressure group, while a $9.2 \%$ increase was seen in the low blood pressure group. In addition, the number of patients who showed an increase of ONSD above $10 \%$ was higher in the normal blood pressure group compared to the low blood pressure group. Mean values of ONSD and $\mathrm{rSO}_{2}$ during T0 to T3 did not show any significant difference between the two groups. If we consider an increase of ONSD more than $10 \%$ predicts an increased ICP during $\mathrm{CO}_{2}$ pneumoperitoneum and Trendelenburg position, the normal blood pressure group shows a higher probability of increased ICP than the low blood pressure group. In this study, we used an ONSD value of $5.5 \mathrm{~mm}$ as the cutoff for prediction of increased ICP although other study suggested it should be $5.8 \mathrm{~mm}$ [11]. Since ONSD values differ according to ethnicity [19], the results obtained from a Caucasian population may not accurately reflect the association between increased ICP and ONSD in the Korean population. Therefore, we used the cutoff value of $5.5 \mathrm{~mm}$ as it was established among the Korean population [12].

ONSD increased due to steep Trendelenburg position and $\mathrm{CO}_{2}$ pneumoperitoneum during RALRP. The dural sheath of the optic nerve is in close contact with the CSF in the intra-

Table 5. Regional Cerebral Oxygen Saturation $\left(\mathrm{rSO}_{2}\right)$ during Robot-assisted Laparoscopic Radical Prostatectomy in Normal Blood Pressure and Low Blood Pressure Groups

\begin{tabular}{cccc}
\hline Regional cerebral oxygen saturation & Normal blood pressure group $(n=27)$ & Low blood pressure group $(n=24)$ & Adjusted P value \\
\hline $\mathrm{rSO}_{2}(\%)$ & & & $65.8 \pm 5.2$ \\
$\mathrm{~T} 0$ & $64.5 \pm 5.3$ & $67.5 \pm 4.9$ & 0.592 \\
$\mathrm{~T} 1$ & $66.7 \pm 6.8$ & $68.8 \pm 4.8$ & 0.901 \\
$\mathrm{~T} 2$ & $66.2 \pm 5.9$ & $69.0 \pm 5.4$ & 0.152 \\
$\mathrm{~T} 3$ & $67.3 \pm 5.6$ & 0.564 \\
\hline
\end{tabular}

Values are presented as mean \pm SD. Adjusted $P$ value indicates the Bonferroni-corrected $P$ value. T0, supine position before anesthesia induction (baseline); T1, $1 \mathrm{~h}$ after 30-degree Trendelenburg position with $\mathrm{CO}_{2}$ pneumoperitoneum; T2, $2 \mathrm{~h}$ after 30-degree Trendelenburg position with $\mathrm{CO}_{2}$ pneumoperitoneum; T3, 10 min after returning to supine position without $\mathrm{CO}_{2}$ pneumoperitoneum at the end of surgery.
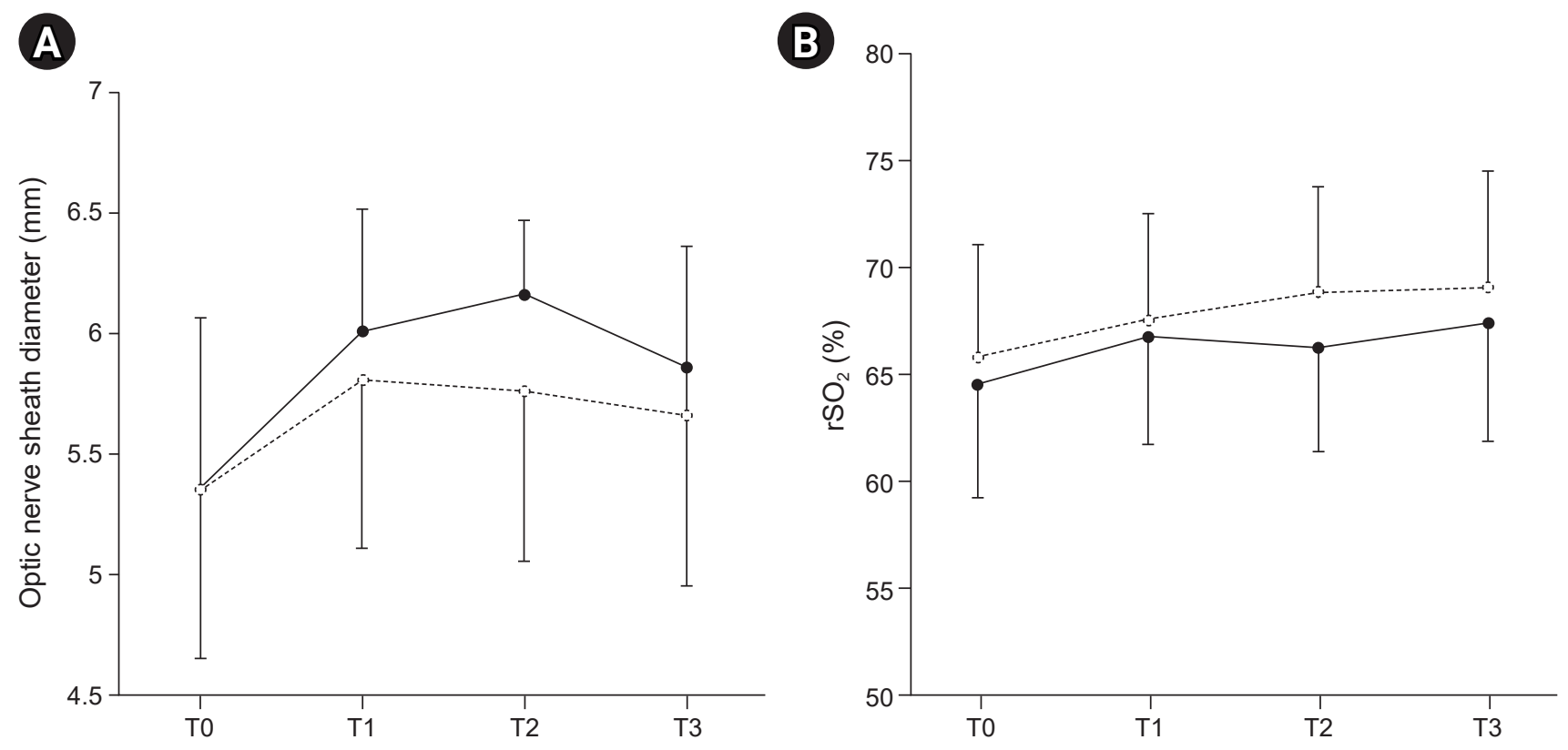

Fig. 3. Changes in optic nerve sheath diameter (A) and regional cerebral oxygen saturation (B) $\left(\mathrm{rSO}_{2}\right)$ in normal (filled circle) and low blood pressure groups (open circle). Data are mean with SD. TO, supine position before anesthesia induction (baseline); T1, $1 \mathrm{~h}$ after 30-degree Trendelenburg position with $\mathrm{CO}_{2}$ pneumoperitoneum; T2, 2 h after 30-degree Trendelenburg position with $\mathrm{CO}_{2}$ pneumoperitoneum; T3, 10 min after returning to supine position without $\mathrm{CO}_{2}$ pneumoperitoneum at the end of surgery. 
cranial subarachnoid space. Hence, any increase or decrease of ICP is directly transmitted to the CSF in the optic nerve sheath. The subarachnoid space surrounding the optic nerve sheath has an elastic trabecular structure $[8,11,14]$. It is most distensible $3 \mathrm{~mm}$ behind the papilla in the globe. Due to such distensibility, the optic nerve sheath inflates within a few minutes of exposure to increased ICP $[1,7,14,17]$. The Trendelenburg position has an effect to produce a moderate increase in ICP as seen with intracranial monitoring. $\mathrm{CO}_{2}$ pneumoperitoneum causes an increased intra-abdominal pressure. Such increases in intra-abdominal pressure can impair CSF drainage with resultant elevation of ICP [20]. In conjunction with increased intra-abdominal pressure, the elevated content of arterial $\mathrm{CO}_{2}$ during $\mathrm{CO}_{2}$ pneumoperitoneum increases the cerebral blood flow. As a result, ICP is expected to increase $[1,3]$. In this study, values of $\mathrm{PaCO}_{2}$ analyzed after pneumoperitoneum showed a tendency towards an increase. Hence, the increased $\mathrm{PaCO}_{2}$ might partially contribute to the increased ICP, although $\mathrm{EtCO}_{2}$ was near to normocapnia after adjusting for the respiratory rate.

The cerebral perfusion pressure (CPP) is known as MAP minus central venous pressure or ICP. If this equation was entirely true, ICP would equal to MAP-CPP implying no venous involvement [21]. Therefore, we can assume that if CPP is constant, the low blood pressure group will have lower ICP than the normal blood pressure group. However, ICP has a dynamic component which is affected by the brain, intracranial blood flow, and CSF. The average male intracranial volume including brain and CSF is around 1,473 $\mathrm{ml}$ and the brain receives blood flow approximately $14 \%$ of cardiac output $(700 \mathrm{ml} / \mathrm{min})$. At any moment in time, the intracranial blood volume is $100-130 \mathrm{ml}$. Therefore, brain, blood flow, and CSF should be considered during regulation of ICP $[20,21]$.

ICP is regulated by arterial and venous influence. Previous study suggested that vena caval pressure can reflect CSF pressure due to the lack of valves in the cranio-vertebral venous system, and retinal venous distension could reflect intracranial venous pressure. ICP is affected by changes in vascular pressure especially with the greater importance of the venous system. Specifically, increasing central venous pressure results in increasing ICP when compliance is lost $[1,16,20,21]$. We assume that the effect of an attenuation in increase of ONSD in the low blood pressure group is related to lower intracranial vascular pressure compared to the normal blood pressure group.
Cerebral oxygenation can be monitored by $\mathrm{rSO}_{2}$ and it reflects cerebral perfusion. $\mathrm{rSO}_{2}$ is comprised of $25 \%$ arterial and $75 \%$ venous blood according to the manufacturer. Cerebral blood volume changes with variation in $\mathrm{PaCO}_{2}$ [16] Carbon dioxide insufflated abdominally during pneumoperitoneum is absorbed into the systemic circulation and is exhaled with ventilation. We could observe a slight increase in $\mathrm{PaCO}_{2}$ during time points of $\mathrm{T} 1$ and $\mathrm{T} 2$ although it did not exceed $45 \mathrm{mmHg}$. In addition to this increase of $\mathrm{PaCO}_{2}$, the steep head down tilt position is known to cause an increase in cerebral blood volume. Previous study measured cerebral blood volume using near-infrared time-resolved spectroscopy. Cerebral blood volume increased to near $10 \%$ during head down tilt position compared to the supine position [22]. Our study showed changes in $\mathrm{rSO}_{2}$ over time, with a tendency to increase in both groups. Increased cerebral blood volume resulting from increased $\mathrm{PaCO}_{2}$ and steep head down tilt position might have resulted in a tendency for $\mathrm{rSO}_{2}$ to increase. However, this increase of $\mathrm{rSO}_{2}$ was within $5 \%$ in both groups. Similar to our study, changes in $\mathrm{rSO}_{2}$ were within $3 \%$ in previous study [22].

Our study includes several limitations. First, transient blood pressure changes above or below of target blood pressure were observed. However, the duration of such blood pressure change was within a minute. We assume that transient blood pressure effect beyond the target blood pressure would not be so potent as to affect the overall results of this study. Second, the operation time of $\mathrm{T} 2$ varied depending on surgeon. Although T2 was defined as two hours after pneumoperitoneum and Trendelenburg position, some cases of RALRP had to return to supine position before fulfilling the expected two hours. However, such cases had less than 15 min differences compared to the two-hour fulfilled $\mathrm{T} 2$.

In conclusion, both groups showed significant increases in ONSD during $\mathrm{CO}_{2}$ pneumoperitoneum and steep Trendelenburg position compared to baseline. The low blood pressure group demonstrated an effect in maintaining an increase of ONSD less than $10 \%$ during $\mathrm{CO}_{2}$ pneumoperitoneum and Trendelenburg position. However, mean values for ONSD and $\mathrm{rSO}_{2}$ during $\mathrm{T} 0$ to $\mathrm{T} 3$ did not show any significant differences between the two groups.

\section{ACKNOWLEDGMENTS}

This study was supported by Keimyung University Research Grant of 2020. 


\section{CONFLICTS OF INTEREST}

No potential conflict of interest relevant to this article was reported.

\section{DATA AVAILABILITY STATEMENT}

The datasets generated durig and/or analyzed during the current study are available from the corresponding author on resonable requet.

\section{AUTHOR CONTRIBUTIONS}

Data curation: Ji Hee Hong. Formal analysis: Ji Hee Hong, Ji Hoon Park. Funding acquisition: Ji Hee Hong. Methodology: Ji Hee Hong. Project administration: Ji Hee Hong. Writing - original draft: Ji Hee Hong. Writing - review \& editing: Ji Hee Hong. Investigation: Ji Hee Hong, Ji Seob Kim, Hyung Jun Kim. Resources: Ji Hoon Park. Supervision: Ji Hee Hong.

\section{ORCID}

Ji Hoon Park, https://orcid.org/0000-0003-4776-5206

Ji Hee Hong, https://orcid.org/0000-0002-6679-3088

Ji Seob Kim, https://orcid.org/0000-0002-8273-8644

Hyung Jun Kim, https://orcid.org/0000-0002-6518-3755

\section{REFERENCES}

1. Kim MS, Bai SJ, Lee JR, Choi YD, Kim YJ, Choi SH. Increase in intracranial pressure during carbon dioxide pneumoperitoneum with steep trendelenburg positioning proven by ultrasonographic measurement of optic nerve sheath diameter. J Endourol 2014; 28: 801-6.

2. Whiteley JR, Taylor J, Henry M, Epperson TI, Hand WR. Detection of elevated intracranial pressure in robot-assisted laparoscopic radical prostatectomy using ultrasonography of optic nerve sheath diameter. J Neurosurg Anesthesiol 2015; 27: 155-9.

3. Choi ES, Jeon YT, Sohn HM, Kim DW, Choi SJ, In CB. Comparison of the effects of desflurane and total intravenous anesthesia on the optic nerve sheath diameter in robot assisted laparoscopic radical prostatectomy: a randomized controlled trial. Medicine (Baltimore) 2018; 97: e12772.

4. You AH, Song Y, Kim DH, Suh J, Baek JW, Han DW. Effects of positive end-expiratory pressure on intraocular pressure and optic nerve sheath diameter in robot-assisted laparoscopic radical prostatectomy: a randomized, clinical trial. Medicine
(Baltimore) 2019; 98: e15051.

5. Kim Y, Choi S, Kang S, Park B. Propofol affects optic nerve sheath diameter less than sevoflurane during robotic surgery in the steep trendelenburg position. Biomed Res Int 2019; 2019: 5617815.

6. Robba C, Santori G, Czosnyka M, Corradi F, Bragazzi N, Padayachy L, et al. Optic nerve sheath diameter measured sonographically as non-invasive estimator of intracranial pressure: a systematic review and meta-analysis. Intensive Care Med 2018; 44: 1284-94.

7. Robba C, Bacigaluppi S, Cardim D, Donnelly J, Bertuccio A, Czosnyka M. Non-invasive assessment of intracranial pressure. Acta Neurol Scand 2016; 134: 4-21.

8. Robba C, Cardim D, Tajsic T, Pietersen J, Bulman M, Donnelly J, et al. Ultrasound non-invasive measurement of intracranial pressure in neurointensive care: a prospective observational study. PLoS Med 2017; 14: e1002356.

9. Ali MA, Hashmi M, Shamim S, Salam B, Siraj S, Salim B. Correlation of optic nerve sheath diameter with direct measurement of intracranial pressure through an external ventricular drain. Cureus 2019; 11: e5777.

10. Ozturk Z, Atalay T, Arhan E, Aydin K, Serdaroglu A, Hirfanoglu $\mathrm{T}$, et al. The efficacy of orbital ultrasonography and magnetic resonance imaging findings with direct measurement of intracranial pressure in distinguishing papilledema from pseudopapilledema. Childs Nerv Syst 2017; 33: 1501-7.

11. Dubost C, Le Gouez A, Jouffroy V, Roger-Christoph S, Benhamou D, Mercier FJ, et al. Optic nerve sheath diameter used as ultrasonographic assessment of the incidence of raised intracranial pressure in preeclampsia: a pilot study. Anesthesiology 2012; 116: 1066-71.

12. Lee SU, Jeon JP, Lee H, Han JH, Seo M, Byoun HS, et al. Optic nerve sheath diameter threshold by ocular ultrasonography for detection of increased intracranial pressure in Korean adult patients with brain lesions. Medicine (Baltimore) 2016; 95: e5061.

13. Lee B, Koo BN, Choi YS, Kil HK, Kim MS, Lee JH. Effect of caudal block using different volumes of local anaesthetic on optic nerve sheath diameter in children: a prospective, randomized trial. Br J Anaesth 2017; 118: 781-7.

14. Padayachy LC, Padayachy V, Galal U, Gray R, Fieggen AG. The relationship between transorbital ultrasound measurement of the optic nerve sheath diameter (ONSD) and invasively measured ICP in children: part I: repeatability, observer variability and general analysis. Childs Nerv Syst 2016; 32: 1769-78.

15. Cimilli Ozturk T, Demir H, Yorulmaz R, Ozdemir S, Isat G, Ecmel Onur O. Assessment of intra-interobserver reliability of the 
sonographic optic nerve sheath diameter measurement. Kaohsiung J Med Sci 2015; 31: 432-6.

16. Matsuoka T, Ishiyama T, Shintani N, Kotoda M, Mitsui K, Matsukawa T. Changes of cerebral regional oxygen saturation during pneumoperitoneum and Trendelenburg position under propofol anesthesia: a prospective observational study. BMC Anesthesiol 2019; 19: 72.

17. Hong JH, Jung SW, Park JH. The effect of speed of normal saline injection on optic nerve sheath diameter in thoracic epidural anesthesia. Pain Physician 2019; 22: E325-32.

18. Moretti R, Pizzi B. Ultrasonography of the optic nerve in neurocritically ill patients. Acta Anaesthesiol Scand 2011; 55: 644-52.

19. Yin G, Wang YX, Zheng ZY, Yang H, Xu L, Jonas JB; Beijing Eye Study Group. Ocular axial length and its associations in Chi- nese: the Beijing eye study. PLoS One 2012; 7: e43172.

20. Choi SH, Lee SJ, Rha KH, Shin SK, Oh YJ. The effect of pneumoperitoneum and Trendelenburg position on acute cerebral blood flow-carbon dioxide reactivity under sevoflurane anaesthesia. Anaesthesia 2008; 63: 1314-8.

21. Wilson MH. Monro-Kellie 2.0: the dynamic vascular and venous pathophysiological components of intracranial pressure. J Cereb Blood Flow Metab 2016; 36: 1338-50.

22. Tanaka N, Yamamoto M, Abe T, Osawa T, Matsumoto R, Shinohara N, et al. Changes of cerebral blood volume during robot-assisted laparoscopic radical prostatectomy: observational prospective study using near-infrared time-resolved spectroscopy. J Endourol 2019; 33: 995-1001. 